\title{
Research Paper: Optimization and Validation of a novel Nebulizer-Assisted Liquid Phase Microextraction Followed by HPLC-DAD for Diazinon Analysis in Plasma Samples
}

\author{
Reza Mohammadzaheri $^{1,2}$ (D), Mehdi Ansari Dogaheh ${ }^{3}$ (D), Maryam Kazemipour ${ }^{1,2}$ (D), Kambiz Soltaninejad ${ }^{4^{*}}$ (iD) \\ 1. Department of Chemistry, Science and Research Branch, Islamic Azad University, Kerman, Iran. \\ 2. Department of Chemistry, Faculty of Medicine, Kerman University of Medical Sciences, Kerman, Iran. \\ 3. Department of Pharmaceutics, Faculty of Pharmacy, Kerman Medical Sciences University, Kerman, Iran \\ 4. Department of Forensic Toxicology, Legal Medicine Research Center, Legal Medicine Organization, Tehran, Iran.
}

$\begin{aligned} & \text { Use your device toscan } \\ & \text { and read the artice online }\end{aligned}$
$\begin{aligned} & \text { Nebulizer-Assisted Liquid Phase Microextraction Followed by HPLC-DAD for Diazinon Analysis in Plasma Samples. Interna- } \\ & \text { tional Journal of Medical Toxicology and Forensic Medicine. 2019; 9(4):221-232. https://doi.org/10.32598/ijmtfm.v9i4.26167 }\end{aligned}$
dol https://doi.org/10.32598/ijmttm.v9i4.26167

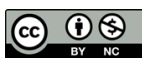

Article info:

Received: 04 Apr 2019

First Revision: 24 Apr 2019

Accepted: 08 Aug 2019

Published: 01 Oct 2019

\begin{abstract}
A B S T R A C T
Background: Diazinon is among the most prevalently used broad-spectrum organophosphates insecticides. Diazinon toxicity depends on its blood concentration. The current study aimed to extract and determine diazinon in plasma samples using a new Nebulizer -Assisted LiquidPhase Microextraction followed by High-Performance Liquid Chromatography with DiodeArray Detection (NALPME-HPLC-DAD).

Methods: Several effective parameters, including the type and volume of extracting solvent, $\mathrm{pH}$, surfactant, salt amount, and nebulizing, were evaluated and optimized to find the best condition for the extraction and determination of diazinon in plasma samples using High-Performance Liquid Chromatography with Diode-Array Detection (HPLC-DAD). Additionally, the Plackett-Burman design was employed in preliminary experiments to screen the most appropriate parameters. Furthermore, we selected a central composite design to determine the best experimental conditions in NALPME-HPLC-DAD.

Results: In an optimum condition, $412 \mu \mathrm{L}$ of toluene (as extracting solvent) and nebulizing with nitrogen gas as dispersing and emulsification, sodium lauryl sulfate $(2.8 \% \mathrm{w} / \mathrm{v})$ and $100 \mu \mathrm{L}$ sodium chloride $(1.5 \% \mathrm{w} / \mathrm{v})$ in $\mathrm{pH} 8.1$ were selected. The standard calibration curves for diazinon were linear with the concentration range of $0.5-4 \mu \mathrm{g} / \mathrm{mL}$ with a correlation coefficient of 0.9992. The Limit Of Detection (LOD) and Limit Of Quantification (LOQ) for diazinon were $0.123 \mu \mathrm{g} / \mathrm{mL}$ and $0.372 \mu \mathrm{g} / \mathrm{mL}$, respectively.
\end{abstract}

Conclusion: The proposed method was simple, accurate, precise, and sensitive for analyzing diazinon in the plasma samples. This method can be used for analyzing plasma diazinon concentrations in acute poisoning cases in clinical and forensic toxicology analyses.

\section{* Corresponding Author:}

Kambiz Soltaninejad, PhD.

Address: Department of Forensic Toxicology, Legal Medicine Research Center, Legal Medicine Organization, Tehran, Iran.

Tel: +98 (21) 55613731

E-mail: kamsoltaninejad@gmail.com 


\section{Introduction}

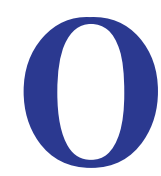

rganophosphates (OPs) are widely used as pesticides in the world, and their acute poisoning remains a major public health concern among developing countries. Due to their toxicity and complications, OPs poisoning has imposed a necessary medical burden on healthcare systems [1, 2]. In these countries, because of feasible access (due to improper legal restrictions), OPs are considered as a significant cause of self-poisoning [3-5]. Therefore, OPs poisoning is considered as a major cause of morbidity and mortality in clinical and forensic toxicology [5-7].

Diazinon is among the most frequently used broadspectrum OPs insecticides worldwide [4]. The primary action mechanism of diazinon in acute poisoning is the irreversible inhibition of acetylcholinesterase activity in blood and the nervous system [8]. However, diazinon toxicity is directly proportional to its concentration in blood and tissues. Accordingly, determining diazinon in biological fluids in acute poisoning cases is the major issue in clinical and forensic toxicology [7, 9]. Several analytical methods have been demonstrated for diazinon analysis in biosamples for clinical and forensic toxicological settings [10-13]. For example, Park et al. developed a Solid-Phase Extraction (SPE) and Gas Chromatography/Mass Spectrometry (GC/MS) for analyzing diazinon, chlorpyrifos, malathion, and parathion in postmortem blood samples [10].

Moreover, in another study, a High-Performance Liquid Chromatography with Diode-Array Detector (HPLC-DAD) has been developed for measuring 11 organophosphorus pesticides, including diazinon in the serum and urine of acute poisoning cases [12]. In this method, after serum deproteinization by acetonitrile, an aliquot of the samples was injected into HPLC column using acetonitrile-water as a mobile phase [12]. Validated liquid chromatography with tandem MS method for simultaneous screening of 215 pesticide types, including diazinon, has been established for general unknown screening for pesticides in blood and gastric contents in forensic toxicology setting [13]. In this study, the samples were prepared by the modified Quick, Easy, Cheap, Effective, Rugged, and Safe (QuEChERS) method. A modified QuEChERS that uses dispersive solidphase extraction for a small amount of sample was applied for quick and convenient sample preparation [13].

The development of simple, fast, low-cost, user- and environment-friendly sample preparation methods is a crucial concern in analytical chemistry and toxicology. The miniaturization of conventional liquid-liquid extraction methods by reducing the acceptor-to-donor ratio was recently encouraged [14]. In Liquid-Phase Micro Extraction (LPME), extraction with a small volume of a water-immiscible solvent from a water-based sample containing analytes (donor phase) has been developed. LPME can be divided into three main classes, including Single-Drop Micro Extraction (SDME), Dispersive Liquid-Liquid Micro Extraction (DLLME), and HollowFiber Micro Extraction (HF-LPME) [14].

DLLME is a primary LPME technique; it is a simple, inexpensive, and environment-friendly extraction method. Furthermore, it has advantages like a high enrichment factor due to the large contact surface area of the extraction solvent, and low usage of toxic organic solvent $[15,16]$. DLLME is suitable for extracting various water-based samples using low-density and highdensity extraction solvents. Applying less toxic solvents and more conveniently practical procedures are suggested in DLLME. Numerous novel and special devices for collecting low-density extraction solvent are also used. In addition, various dispersion techniques, such as air-assisted, ultrasound-assisted, vortex-assisted, surfactant-assisted, and microwave-assisted DLLME are developed. Combining DLLME with other extraction techniques (e.g. solid-phase extraction and nano techniques) are also introduced [17]. The main disadvantage of DLLME is the lack of selective extraction technique and the presence of matrix interferences co-extractives, especially in complex matrix samples [14].

Several parameters, including the type and volume of extracting and disperser solvent, $\mathrm{pH}$, and salt amount impact the efficiency of extraction method; the optimization of these factors is the best extraction method of the analytes from the samples [18]. Selecting suitable parameters via trial and error is time-consuming, from which the optimal parameter settings may not be readily obtained. Therefore, evaluating statistical models and experimental designs is effective for the optimization of methods. A Plackett-Burman design, as well as a Central Composite Design (CCD) were used to identify the optimum conditions required for the analysis during method development [19-21].

The present study aimed to introduce a fast, simple, and novel nebulizer-assisted liquid-phase microextraction, followed by HPLC-DAD (NALPME-HPLC-DAD) for the extraction and determination of diazinon in human plasma samples for routine analysis in clinical and forensic toxicology laboratories. 


\section{Materials and Methods}

HPLC-grade methanol, acetonitrile, water, toluene, chloroform, and dichloromethane were obtained from Merck (Darmusdat, Germany). HPLC-grade standard materials of diazinon, pirimiphos-methyl, azinphosethyl, and chlorpyrifos were purchased from Dr. Ehrenstofer GmbH (Augsburg, Germany). All other chemicals and reagents were of analytical grade and purchased from Merck (Darmstadt, Germany). Nitrogen gas (purity $=99.9 \%$ ) was obtained from Roham Gas Company (Tehran, Iran). The stock solution of diazinon $(100 \mu \mathrm{g} /$ $\mathrm{mL}$ ) was prepared by methanol and stored at $4^{\circ} \mathrm{C}$.

The HPLC system (Smartline Series 1200, Knauer, Berlin, Germany) consisted of a Knauer 1050 HPLC pump at a flow rate of $1 \mathrm{~mL} / \mathrm{min}$ and a diode -array detector (K-2800, Knauer, Germany). Moreover, ChromGate software (version 3.3.2., Knauer, Germany) was used for data analysis. The chromatography was isocratically performed on a Nucleosil ${ }^{\circledR}$ C18 analytical column (250 $\mathrm{mm} \times 4.6 \mathrm{~mm}$ ID, $5 \mu \mathrm{m}$ particle size, Perfectsil Target $\left.{ }^{\circledR}\right)$. An RP-18 guard column was fitted at the upstream of the analytical column. The mobile phase was a mixture of acetonitrile/phosphate buffer pH $2.3(63: 37 \mathrm{v} / \mathrm{v})$.

The standard solutions were prepared by the serial dilution of diazinon stock solution $(100 \mu \mathrm{g} / \mathrm{mL})$ in the range of $0.5,1.0,1.5,2,2.5,3$, and $4 \mu \mathrm{g} / \mathrm{mL}$. Stock solution $(2.5 \mu \mathrm{g} / \mathrm{mL})$ of pirimiphos-methyl (I.S) in methanol was prepared and stored at $-20^{\circ} \mathrm{c}$. The stock and standard solutions were prepared daily and stored in the dark at $4^{\circ} \mathrm{C}$. All solutions were used on the day they were prepared.

Blank plasma samples (drug-free) were provided by healthy volunteers in our laboratory. The plasma samples were kept frozen at $-20 \circ \mathrm{C}$ before the analysis. Ten $\mu \mathrm{L}$ of pirimiphos-methyl (internal standard, IS) $(2.5 \mu \mathrm{g} /$ $\mathrm{mL}$ ) was added to each sample and vortexed; then, 100 $\mu \mathrm{L}$ Sodium Lauryl Sulfate (SLS) $(2.8 \%, \mathrm{w} / \mathrm{v})$ and 100 $\mu \mathrm{L}$ sodium chloride $(1.5 \%, \mathrm{w} / \mathrm{v})$ were added to the glass tubes containing $1 \mathrm{~mL}$ blank plasma and $2 \mathrm{~mL}$ phosphate buffer with $\mathrm{pH}$ 8.1. The final solution was subjected to the NALPME process.

\section{NALPME procedure}

In this method, we used a nitrogen gas nebulizer device for dispersing the mixture. In total, $314 \mu \mathrm{L}$ toluene (extracting solvent) was rapidly injected using a microsyringe (Hamilton, Reno, NV, USA) to a conical test tube containing a plasma sample. It resulted in the fine droplets of toluene to form a cloudy solution. Next, the test tube contents were transferred into a second test tube by nebulizer, in a few seconds and a stable cloudy emulsion has been formed (Figure 1). The analytes were extracted into the fine droplets of toluene. After centrifugation (15 $\mathrm{min}$ at $3500 \mathrm{rpm}$ ), the supernatant was transferred entirely into a clean conical test tube using a microsyringe; after drying by the solvent evaporation under nitrogen stream, the residue was dissolved in 20 $\mu \mathrm{L}$ of HPLC mobile phase and injected into the HPLC.

\section{The optimization of NALPME procedure}

The type and volume of the extracting solvent, the amounts of salt and surfactant, $\mathrm{pH}$, sonication, and nebulizing conditions were evaluated. Plackett-Burman design was used in preliminary experiments to screen the most appropriate parameters (Table 1). Furthermore, three-dimensional response surface and contour plots were drawn. In this study, the 4-factor-2-level Central Composite Design (CCD) [each numeric factor varies over 5 levels: plus and minus alpha (axial points), plus and minus (factorial points), and the center point; and if categorical factors are added, the CCD will be duplicated for every combination of the categorical factor levels] was employed to draw response- surface graphs. This process helped to determine the optimal conditions and investigate parabolic interactions between the parameters; the volume of extraction solvent (toluene), salt percentage $(\mathrm{NaCl})$, surfactant percentage (SLS), and $\mathrm{pH}$. This design permitted the response-surface to be modeled by fitting a second-order polynomial with the number of experiments equal to 21 , to be executed as per CCD design. The experiments were executed according to the design listed in Table 4, and the measured responses are presented in the same table.

\section{HPLC method validation}

The parameters considered for the validation included the following: linearity, precision, accuracy, limits of detection and quantification, and selectivity [21].

The calibration curves were constructed with 7 concentrations ranging from 0.5 to $4 \mu \mathrm{g} / \mathrm{mL}$ of diazinon. Each concentration level was prepared in triplicate and analyzed three times. Calibration curves were constructed by plotting the concentration of analyte versus peak area response. The linearity was evaluated by the least square regression method.

The Limit Of Detection (LOD) and Limit Of Quantification (LOQ) were calculated according to $\mathrm{LOD}=3.3 \sigma / \mathrm{S}$ 
and $\mathrm{LOQ}=10 \sigma / \mathrm{S}$; where $\sigma$ is the standard deviation of the response, and $\mathrm{S}$ is the slope of the calibration curve.

The method precision was determined by repeatability (intra-day) and intermediate precision (inter-day), and it was expressed as Relative Standard Deviation (RSD). Five replicate injections of the standard solutions of diazinon were prepared at concentrations ranging from 0.5 to $4 \mu \mathrm{g} / \mathrm{mL}$. The intra-day variation was assessed by the same analyst over a day, while inter-day precision was carried out for three consecutive days.

The accuracy of the method was tested by 5 replicates of three different samples of diazinon at known concentrations; then, it was compared with its right concentration. The accuracy was assessed by the recovery percentage.

The selectivity was evaluated by comparing the chromatograms of different batches of blank plasma spiked with diazinon, IS, tramadol, azinphos-ethyl, pirimiphosmethyl, and chlorpyrifos $(2 \mu \mathrm{g} / \mathrm{mL})$.

Design Expert (Stat-Ease Inc., Minneapolis, MN, USA) software was used for the regression and graphical examination of the experimental results.

\section{Results}

The variables of extraction efficiency were selected based on preliminary experiments on the distinct responses of the variables to achieve maximum recovery. The 9 factors (extraction variables), the levels, and experimental designs are listed in Table 1. The sonication, type, and volume of dispersive solvents negatively affected the maximum recovery. The other parameters positively impacted the recovery and were selected for further optimization $(\mathrm{P}<0.05)$ (Table 2, Figure 2). Toluene (as extracting solvent) was selected for examination; because it positively affected all variables, and it was fixed to experiments.

The analyzing response-surface plots indicated the effects of the parameters on the maximum recovery. In CCD design, 5 levels were coded $(-\alpha,-1,0,+1,+\alpha)$. Center points were coded as 0 and -used to estimate pure error; factorial levels were coded as \pm 1 , and axial points/ star points were coded as $\pm \alpha$. The range of the independent variables used in this study in terms of actual and coded values is summarized in Table 3. The maximum diazinon recovery was obtained with 21 experiments for 4 factorial designs at 5 levels and 5 replicated points. The actual value and statistically predicted diazinon concentration for experiments are presented in Table 4. The mathematical model was as follows:

Recovery $=+93.75+1.72 * A+1.82 * B-1.01 * C+2.72$

$* D-0.67 * A * C+3.65 * A * D+0.82 * C * D-3.03 * A 2$

$1.42 * B 2-2.03 * C 2-3.58 * D 2$

This equation represents the relationship of diazinon recovery $(\mathrm{R})$ with the volume of extraction solvent (A), the surfactants concentration (B), the salt concentration $(\mathrm{C})$, and $\mathrm{pH}(\mathrm{D})$ in the coded units. Variables $\mathrm{AC}, \mathrm{AD}$, and $\mathrm{CD}$ had interaction effects on the volume of the extraction of solvent-salt concentration, the volume of the extraction solvent, the $\mathrm{pH}$, and the salt concentration. The adequacy of the CCD model placed in Analysis of Variance (ANOVA) and the importance of the coefficients are

Table 1. Variables and their levels for Plackett-Burman design

\begin{tabular}{|c|c|c|c|}
\hline Factor & Leve 1 & Level 2 & Symbol \\
\hline Chloroform & 200 & 500 & $A$ \\
\hline Methanol & 400 & 900 & B \\
\hline Surfactant concentration (\%w/v) & 1 & 3 & $\mathrm{C}$ \\
\hline Salt concentration (\%w/v) & 1 & 3 & $\mathrm{D}$ \\
\hline Toluene & 200 & 500 & $\mathrm{E}$ \\
\hline $\mathrm{pH}$ & 4 & 10 & $\mathrm{~F}$ \\
\hline Acetonitrile & 400 & 900 & G \\
\hline Nebulizing & Not done & Done & $\mathrm{H}$ \\
\hline Sonication duration(min) & 0 (time) & 10 (time) & 1 \\
\hline
\end{tabular}


Table2. ANOVA results for the proposed Plackett-Burman model

\begin{tabular}{|c|c|c|c|c|c|c|}
\hline \multirow{2}{*}{ Source } & Sum of & \multirow{2}{*}{ df } & Mean & \multirow{2}{*}{$\mathbf{F}$} & $\mathbf{P}$ & \multirow{2}{*}{ Significant } \\
\hline & Squares & & Square & & Prob $>F$ & \\
\hline Model & 6413.033 & 5 & 1282.607 & 31.55966 & 0.0003 & Yes \\
\hline C-SLS & 1786.08 & 1 & 1786.08 & 43.94806 & 0.0006 & Yes \\
\hline D-NaCl & 1200 & 1 & 1200 & 29.52705 & 0.0016 & Yes \\
\hline E-Toluene & 1765.158 & 1 & 1765.158 & 43.43324 & 0.0006 & Yes \\
\hline F-pH & 302.0033 & 1 & 302.0033 & 7.431055 & 0.0344 & Yes \\
\hline H-Spray & 1359.792 & 1 & 1359.792 & 33.45888 & 0.0012 & Yes \\
\hline Residual & 243.8442 & 6 & 40.64071 & - & - & - \\
\hline Cor Total & 6656.878 & 11 & - & - & - & - \\
\hline
\end{tabular}

Table 3. Experimental ranges and the levels of the independent variables for central composite design

\begin{tabular}{cccccccc}
\hline Symbol & Factor & Unit & $\boldsymbol{\alpha}-$ & $\mathbf{1 -}$ & $\mathbf{0}$ & $\mathbf{1 +}$ & $\boldsymbol{\alpha +}$ \\
\hline $\mathrm{A}$ & Toluene & $\mu \mathrm{L}$ & 225 & 300 & 375 & 450 & 525 \\
$\mathrm{~B}$ & $\mathrm{SLS}$ & $\%$ & 0 & 1 & 2 & 3 & 4 \\
$\mathrm{C}$ & $\mathrm{NaCl}$ & $\%$ & 0 & 1 & 2 & 3 & 4 \\
$\mathrm{D}$ & $\mathrm{pH}$ & - & 1 & 4 & 7 & 10 & 13 \\
\hline
\end{tabular}

SLS: Sodium Lauryl Sulphate

International Journal of
Medical Toxicology \& forensic Medicin

observed in Table 5. The significance of each coefficient was determined by F-values (variation of data from mean value) and P-values (probability). F-values and P-values were high and very low, respectively (Table 5).

\section{Discussion}

The obtained results suggested that the model appropriately predicted the experimental result. Low P-values of the linear and quadratic terms were observed for salt concentration, surfactants concentration, and $\mathrm{pH}$. The extraction volume of the solvent had a valid correlation with these parameters. In addition, the values of the interaction effect of the variables were significant. The correctness of the model was also ensured by the multiple correlation coefficients (R2). The R2-values varied from 0 to 1 , and when $\mathrm{R} 2$ value was quite close to 1 , the predicted value was relatively close to the actual value. In other words, the model definitely predicted the actual value and the response was excellent. The correlation coefficient (R2) was calculated as 0.9928 , even less than $1 \%$ of the total variation, which cannot be expressed by the regression model. The predicted multiple correlation coefficient (Pred. R2=0.9642) was in reasonable agreement with the adjusted multiple correlation coefficient (Adj. R2=0.9839).

Additionally, the coefficient of variance $(\mathrm{CV}=1.89 \%)$ was low, which indicates the significant precision and reliability of the obtained experimental data. Adequate precision measures the signal/noise ratio. A ratio $>4$ is demanded. Adequate precision was equal to 34.25 , indicating that the model could be used to navigate the design space. The relation of the diazinon recovery and the independent variables were demonstrated by a three-dimensional response surface diagram. In each 3D curve, the effects of two factors on diazinon recovery are shown, maintaining the other variable constant at zero levels. Figures 3 and 4 indicate the relationship between the extraction solvent volume and salt concentration; the extraction solvent volume, $\mathrm{pH}$, and salt concentration influenced the diazinon recovery. 
Table 4. Experimental conditions according to the central composite design and observed response values

\begin{tabular}{|c|c|c|c|c|c|}
\hline Standard Order & Toluene Volume ( $\mu \mathrm{L}$ ) & $\begin{array}{c}\text { Surfactant } \\
\text { Concentration }(\% \mathrm{w} / \mathrm{v})\end{array}$ & $\begin{array}{c}\text { Salt Concentra- } \\
\text { tion } \\
(\% w / v)\end{array}$ & $\mathrm{pH}$ & $\begin{array}{l}\text { Actual } \\
\text { Recovery }\end{array}$ \\
\hline 1 & 400 & 3 & 1 & 4 & 83.41 \\
\hline 2 & 300 & 2 & 2 & 7 & 94.39 \\
\hline 3 & 300 & 0 & 2 & 7 & 84.92 \\
\hline 4 & 300 & 2 & 2 & 7 & 94.75 \\
\hline 5 & 300 & 4 & 2 & 7 & 91.77 \\
\hline 6 & 200 & 3 & 3 & 10 & 83.18 \\
\hline 7 & 400 & 1 & 3 & 10 & 89.02 \\
\hline 8 & 400 & 1 & 1 & 10 & 89.98 \\
\hline 9 & 300 & 2 & 0 & 7 & 88.07 \\
\hline 10 & 200 & 1 & 3 & 4 & 80.67 \\
\hline 11 & 300 & 2 & 2 & 7 & 93.44 \\
\hline 12 & 200 & 1 & 1 & 4 & 82.25 \\
\hline 13 & 300 & 2 & 2 & 7 & 93.24 \\
\hline 14 & 400 & 3 & 3 & 4 & 78.40 \\
\hline 15 & 500 & 2 & 2 & 7 & 85.44 \\
\hline 16 & 100 & 2 & 2 & 7 & 77.92 \\
\hline 17 & 300 & 2 & 2 & 1 & 73.50 \\
\hline 18 & 300 & 2 & 2 & 7 & 92.60 \\
\hline 19 & 300 & 2 & 4 & 7 & 83.29 \\
\hline 20 & 300 & 2 & 2 & 13 & 85.44 \\
\hline 21 & 200 & 3 & 1 & 10 & 82.25 \\
\hline
\end{tabular}

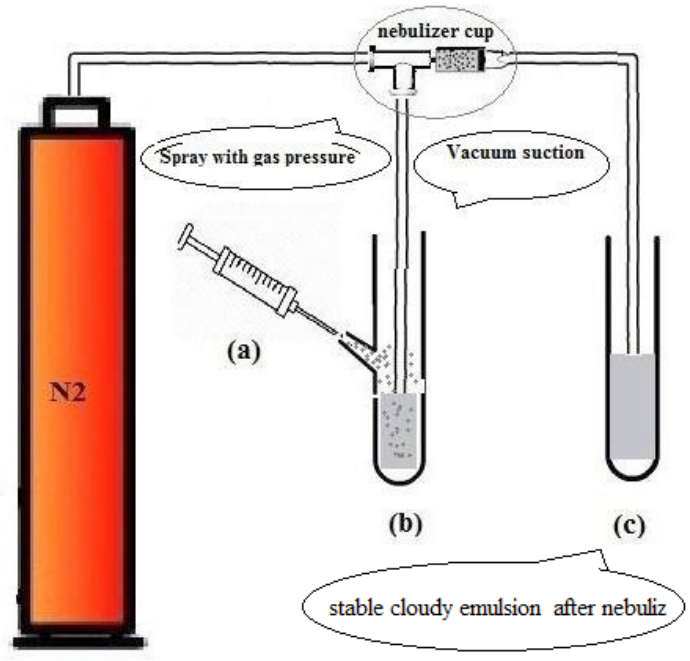

Figure 1. Schematic NALPME procedure

A. In the first step, extraction solvent (toluene) was injected into the conical test tube containing sample rapidly by microsyringe; $\mathrm{B}$. It resulted in fine droplets of toluene to form a cloudy solution. The contents of the test tube by nebulizer transferred into a second test tube ; C. during a few seconds, a stable cloudy emulsion has been formed 
Table 5. ANOVA results for central composite design

\begin{tabular}{|c|c|c|c|c|c|c|}
\hline \multirow{2}{*}{ Source } & Sum of & \multirow{2}{*}{ df } & Mean & \multirow{2}{*}{$\mathbf{F}$} & $\mathbf{P}$ & \multirow{2}{*}{ Significant } \\
\hline & Squares & & Square & & Prob $>F$ & \\
\hline Model & 526.7376 & 11 & 47.88524 & 112.3875 & $<0.0001$ & Yes \\
\hline A-Toluene & 34.69799 & 1 & 34.69799 & 81.43678 & $<0.0001$ & Yes \\
\hline B-SLS & 19.35664 & 1 & 19.35664 & 45.43037 & $<0.0001$ & Yes \\
\hline $\mathrm{C}-\mathrm{NaCl}$ & 11.85081 & 1 & 11.85081 & 27.81405 & 0.0005 & Yes \\
\hline D-PH & 86.62956 & 1 & 86.62956 & 203.3211 & $<0.0001$ & Yes \\
\hline$A C$ & 2.633512 & 1 & 2.633512 & 6.180899 & 0.0346 & Yes \\
\hline$A D$ & 39.03126 & 1 & 39.03126 & 91.60703 & $<0.0001$ & Yes \\
\hline$C D$ & 3.934012 & 1 & 3.934012 & 9.233195 & 0.0140 & Yes \\
\hline$A^{\wedge} 2$ & 168.257 & 1 & 168.257 & 394.902 & $<0.0001$ & Yes \\
\hline $\mathrm{B}^{\wedge} 2$ & 36.88016 & 1 & 36.88016 & 86.55838 & $<0.0001$ & Yes \\
\hline$C^{\wedge} 2$ & 75.54693 & 1 & 75.54693 & 177.31 & $<0.0001$ & Yes \\
\hline$D^{\wedge} 2$ & 235.1549 & 1 & 235.1549 & 551.9126 & $<0.0001$ & Yes \\
\hline Residual & 3.834654 & 9 & 0.426073 & - & - & - \\
\hline Lack of Fit & 1.74137 & 5 & 0.348274 & 0.665507 & 0.6714 & No \\
\hline Pure Error & 2.093285 & 4 & 0.523321 & - & - & - \\
\hline Cor Total & 530.5723 & 20 & - & - & - & - \\
\hline
\end{tabular}

SLS: Sodium Lauryl Sulphate

International Journal of
Medical Toxicology \& forensic Medicine

The standard calibration curves for diazinon were linear with the concentration range of $0.5-4 \mu \mathrm{g} / \mathrm{mL}$, yielding a regression equation $\mathrm{Y}=0.951 \mathrm{X}-0.024$ with a correlation coefficient of 0.9992 . This is generally considered as the evidence of an acceptable fit of the data to the regression line and indicating appropriate linearity over the concentration range (Figure 5).
The obtained results revealed that the LOD and LOQ for diazinon, using this method, were $0.123 \mu \mathrm{g} / \mathrm{mL}$ and $0.372 \mu \mathrm{g} / \mathrm{mL}$, respectively.

Precision for the quality controls in the intra-day and inter-day run are listed in Table 6. These data indicated that the developed method is accurate, reliable, and reproducible.

Table 6. Precision and accuracy for the determination of diazinon in plasma (intra-day: $n=5$; inter-day: $n=5$ series per day, 3 days)

\begin{tabular}{ccccccc}
\hline \multirow{2}{*}{$\begin{array}{c}\text { Diazinon Concen- } \\
\text { tration }(\mu \mathrm{g} / \mathrm{mL})\end{array}$} & \multicolumn{3}{c}{ Intra-Day } & \multicolumn{3}{c}{ Inter-Day } \\
\cline { 2 - 7 } & Mean \pm SD & CV\% & Recovery \pm SD (\%) & Mean \pm SD & CV \% & Recovery $\pm S D(\%)$ \\
\hline 0.5 & $0.445 \pm 0.02$ & 6.10 & $89.08 \pm 2.38$ & $0.45 \pm 0.02$ & 6.40 & $91.24 \pm 2.1$ \\
1 & $0.90 \pm 0.01$ & 1.41 & $90.16 \pm 2.50$ & $0.91 \pm 0.04$ & 4.46 & $91.1 \pm 3.8$ \\
3 & $2.82 \pm 0.13$ & 4.27 & $94.26 \pm 1.27$ & $2.83 \pm 0.11$ & 3.94 & $94.47 \pm 2.4$ \\
\hline
\end{tabular}



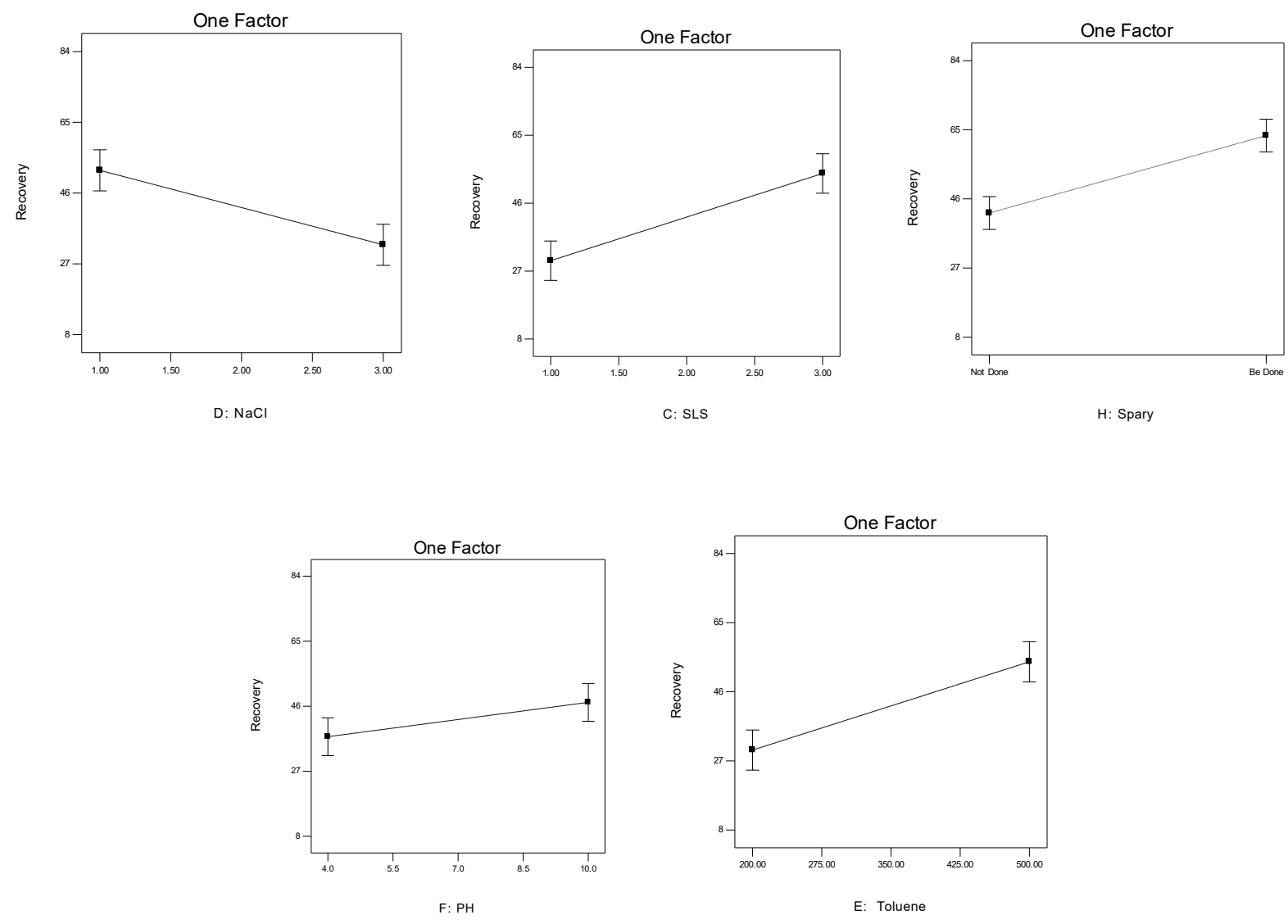

Figure 2. Effective response chart for diazinon recovery for Plackett-Burman method

International Journal of
Medical Toxicology \& Forensic Medicine

C. Effect of surfactant's concentration; D. Effect of salt concentration; E. Effect of volume of the extraction solvent; F. Effect of $\mathrm{pH} ; \mathrm{H}$. Effect of the Nebulizing

The achieved results were expressed as percent recoveries obtained for different diazinon concentrations. Table 6 indicates that the percent recoveries with RSDs comply with the proposed acceptance criteria.
Selectivity is expressed as the capability of a method to distinguish the analyte from all potentially interfering substances. The method selectivity was evaluated by analyzing pools of blank plasma samples to investi-

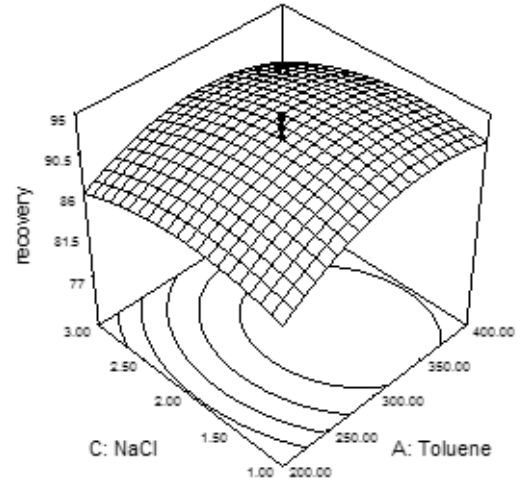

(A)

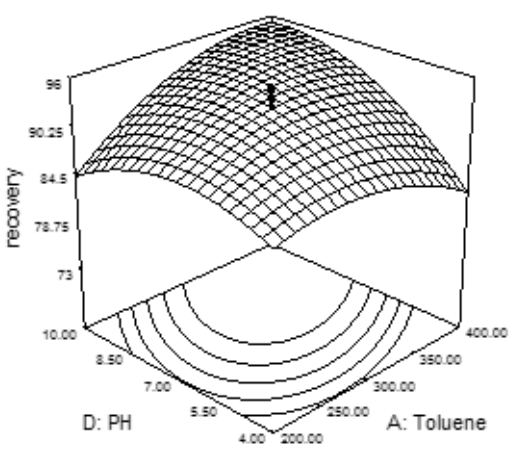

(B)

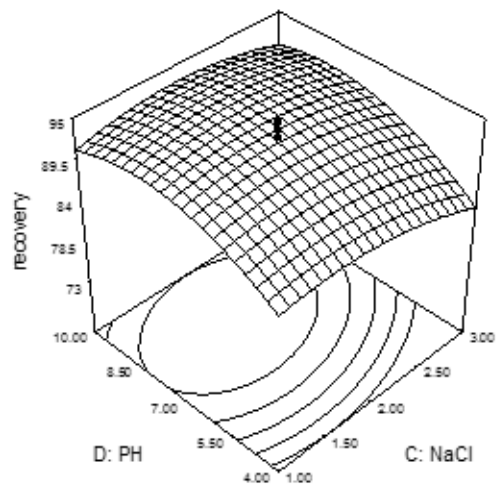

(C)

International Journal of
Medical Toxicology \& Forensic Medicine

Figure3. 3D Surface plots showing the effects of variables with the highest impact on the recovery of the method

A. the effect of the sodium chloride concentration of the volume of toluene; B. the effect of the volume of toluene and $\mathrm{pH}$; $\mathrm{C}$. The effect of the sodium chloride concentration, and the $\mathrm{pH}$ on the recovery of the proposed method 


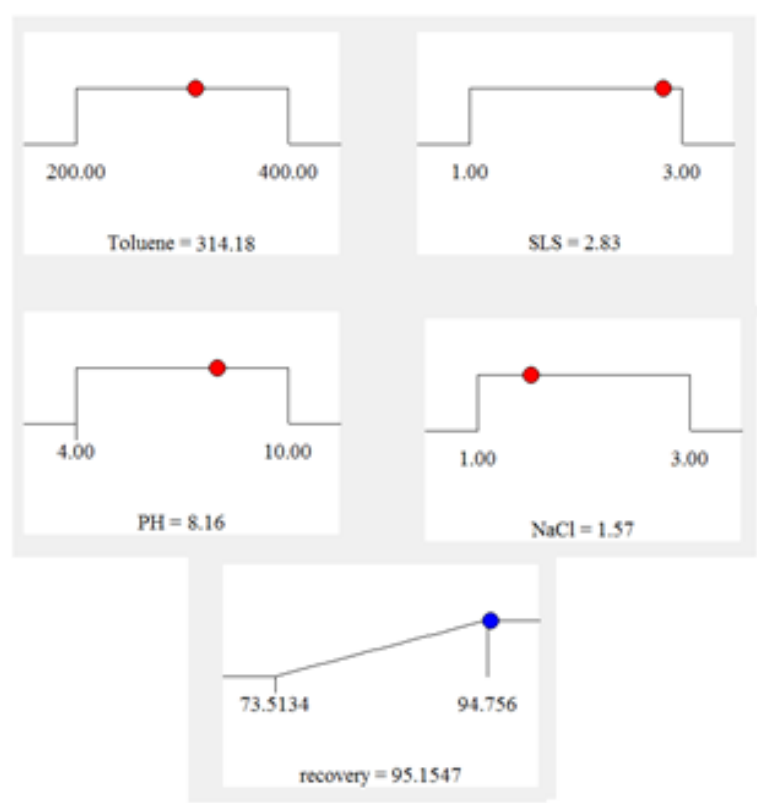

International Journal of
Medical Toxicology \& Forensic Medicine

Figure 4. Desirability ramp for numerical optimization of five goals, namely the initial solution $\mathrm{pH}$, salt concentration, surfactants concentration, extraction solvent volume, and diazinon recovery

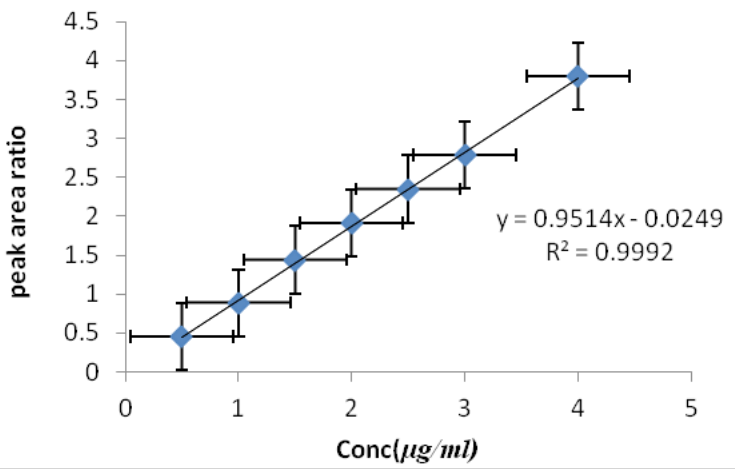

Figure 5. The calibration curve of diazinon in plasma by HPLC-DAD

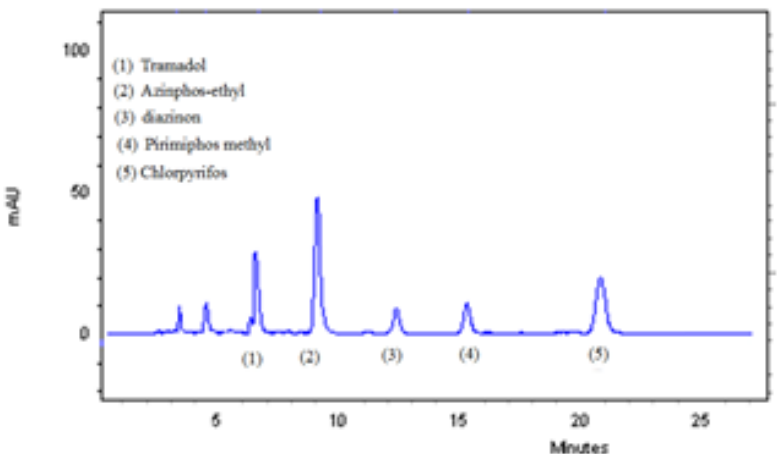

International Journal of
Medical Toxicology \& forensic Medicin

Figure 6. The selectivity of the proposed method for the analysis of diazinon in human plasma samples

The chromatogram of spiked plasma with 1. Tramadol; 2. Azinphos-ethyl; 3. Diazinon; 4. Pirimiphos-methyl; and 5. Chlorpyrifos 
Table 7. Comparing NALPME-HPLC-PDA with other analytical methods for the determination of diazinon in biological samples

\begin{tabular}{|c|c|c|c|c|c|}
\hline Method & Sample & $\operatorname{LOD}(\mu \mathrm{g} / \mathrm{mL})$ & $\begin{array}{l}\text { The Correlation } \\
\text { Coefficient (r2) }\end{array}$ & Recovery (\%) & $\begin{array}{c}\text { Reference } \\
\text { No. }\end{array}$ \\
\hline SPE-GC-MS & Whole Blood & 0.15 & 0.9981 & $78-87$ & [10] \\
\hline SPE-HPLC-DAD & Plasma & 0.15 & 0.998 & 77.7- 86.3 & [11] \\
\hline LLE-HPLC-DAD & $\begin{array}{l}\text { Whole blood, } \\
\text { serum, urine }\end{array}$ & 0.78 & 0.9996 & $\begin{array}{c}\text { Blood and Serum } \\
\quad(97.4-99.01) \\
\text { Urine }(101.1-101.4)\end{array}$ & [12] \\
\hline Mini-QuEChERS-LC-MS-MS & $\begin{array}{l}\text { Whole blood, } \\
\text { gastric content }\end{array}$ & 0.1 & 0.95 & $80-100$ & [13] \\
\hline MEPS-GC-MS-MS & Whole Blood & 0.5 & 0.99 & $61-77$ & [22] \\
\hline DBS-GC-MS-MS & Whole blood & 0.05 & 0.998 & $4.56-5.11$ & [23] \\
\hline NALPME-HPLC-DAD & Plasma & 0.123 & 0.9992 & $89-94$ & Present study \\
\hline
\end{tabular}

SPE-GC-MS: Solid-phase extraction and gas chromatography/mass spectrometry, SPE-HPLC-DAD: Solid-phase extraction and High-Performance Liquid Chromatographic (HPLC) with Diode Array Detector (DAD), LLE-HPLC-DAD: Liquid-Liquid Extraction and High-Performance Liquid Chromatographic (HPLC) with Diode Array Detector, Mini-QuEChERSLC-MS-MS: modified Quick, Easy, Cheap, Effective, Rugged and Safe (QuEChERS) method - Liquid Chromatography with Tandem Mass Spectrometry(LC-MS-MS), MEPS-GC-MS-MS: Microextraction by Packed Sorbent (MEPS)-by Gas Chromatography-tandem Mass Spectrometry (GC-MS-MS), DBS-GC-MS-MS: Dried Blood Spot (DBS) -Gas Chromatography Coupled to Tandem Mass Spectrometry (GC-MS-MS), NALPME-HPLC-DAD: Nebulizer -Assisted Liquid Phase Microextraction-High Performance Liquid Chromatography with Diode-Array Detector

gate possible interferences in the retention times of the studied analytics. The blank plasma had no interference when diazinon and the IS were added. Under optimized conditions, the separation of diazinon and pirimiphosmethyl was completed (Figure 6).

Table 7 summarizes the comparison of the proposed method for the determination of diazinon in plasma samples by the NALPME-HPLC-PDA with previous methods. The LOD, $\mathrm{r} 2$, and the recovery of the present method are suitable, compared with previous methods.

\section{Conclusion}

The present study aimed to develop a fast, selective, and efficient method for the extraction and determination of diazinon from human plasma samples. The NALPME was successfully applied to the rapid and efficient extraction of diazinon before analysis by high-performance liquid chromatography. To achieve maximum extraction efficiency, valid parameters were optimized by the experimental design. The proposed NALPME-HPLCDAD method is accurate, precise, sensitive, and of reasonable linearity; thus, it can be a preferred method for analyzing diazinon in the plasma samples of acute poisoning patients in clinical and forensic toxicology.

\section{Ethical Considerations}

\section{Compliance with ethical guidelines}

This study was ethically approved by the Ethics Committee of the Legal Medicine Organization (Code No. 1054125648).

\section{Funding}

This project was supported by Grant: 1054- 125648 from the Legal Medicine Research Center, Legal Medicine Organization, Tehran, Iran.

\section{Author's contributions}

All authors contributed to designing, running, and writing all parts of the research.

\section{Conflict of interest}

The authors declared no conflicts of interest.

\section{Acknowlegments}

This study is part of the Ph.D. thesis of Reza Mohammadzaeri, proposed and approved by the Department of 
Chemistry, Science and Research Branch, Islamic Azad University, Kerman, Iran.

\section{References}

[1] Adinew GM, Asrie AB, Birru EM. Pattern of acute organophosphorus poisoning at university of gondar teaching hospital, Northwest Ethiopia. BMC Research Notes. 2017; 10:149. [DOI:10.1186/s13104-017-2464-5] [PMID] [PMCID]

[2] Razwiedani LL, Rautenbach P. Epidemiology of organophosphate poisoning in the Tshwane district of South Africa. Environmental Health Insights. 2017; 11:1178630217694149. [DOI:10.1177/1178630217694149] [PMID] [PMCID]

[3] Acikalin A, Dişel NR, Matyar S, Sebe A, Kekec Z, Gokel Y, et al. Prognostic factors determining morbidity and mortality in organophosphatepoisoning. Pakistan Journal of Medical Sciences. 2017; 33(3):534-9. [DOI:10.12669/pjms.333.12395] [PMID] [PMCID]

[4] Soltaninejad K, Shadnia S. History of the use and epidemiology of organophosphorus poisoning. InBasic and Clinical Toxicology of Organophosphorus Compounds. London: Springer; 2014. [DOI:10.1007/978-1-4471-5625-3_2]

[5] Çolak Ş, Erdoğan MÖ, Baydin A, Afacan MA, Kati C, Duran L. Epidemiology of organophosphate intoxication and predictors of intermediate syndrome. Turkish Journal of Medical Sciences. 2014; 44(2):279-82. [DOI:10.3906/sag-1211-31] [PMID]

[6] Pandit V, Seshadri S, Rao SN, Samarasinghe C, Kumar A, Valsalan R. A case of organophosphate poisoning presenting with seizure and unavailable history of parenteral suicide attempt. Journal of Emergencies, Trauma and Shock. 2011; 4(1):132-4. [DOI:10.4103/0974-2700.76825] [PMID] [PMCID]

[7] Soltaninejad K, Faryadi M, Sardari F. Acute pesticide poisoning related deaths in Tehran during the period 2003-2004. Journal of Forensic and Legal Medicine. 2007; 14(6):352-4. [DOI:10.1016/j.jlm.2006.12.011] [PMID]

[8] Karimani A, Mamashkhani Y, Moghadam Jafari A, Akbarabadi M, Heidarpour M. Captopril attenuates diazinoninduced oxidative stress: A subchronic study in rats. Iranian Journal of Medical Sciences. 2018; 43(5):514-22.

[9] United States Environmental Protection Agency. Diazinon: Phase out of all residential uses of the insecticide. Washington: United States Environmental Protection Agency; 2012.

[10] Park MJ, In SW, Lee SK, Choi WK, Park YS, Chung HS. Postmortem blood concentrations of organophosphorus pesticides. Forensic Science International. 2009; 184(1-3):28-31. [DOI:10.1016/j.forsciint.2008.11.008] [PMID]

[11] Abu-Qare AW, Abou-Donia MB. Determination of diazinon, chlorpyrifos, and their metabolites in rat plasma and urine by high-performance liquid chromatography. Journal of Chromatographic Science. 2001; 39(5):200-4. [DOI:10.1093/ chromsci/39.5.200] [PMID]

[12] Cho Y, Matsuoka N, Kamiya A. Determination of organophosphorous pesticides in biological samples of acute poisoning by HPLC with diode-array detector. Chemical and
Pharmaceutical Bulletin. 1997; 45(4):737-40. [DOI:10.1248/ cpb.45.737] [PMID]

[13] Kim HS, Kim J, Suh JH, Han SB. General unknown screening for pesticides in whole blood and Korean gastric contents by liquid chromatography-tandem mass spectrometry. Archives of Pharmacal Research. 2014; 37(10):1317-24 [DOI:10.1007/s12272-014-0440-3] [PMID]

[14] Sarafraz-Yazdi A, Amiri A. Liquid-phase microextraction. Trends in Analytical Chemistry. 2010; 29(1):1-14 [DOI:10.1016/j.trac.2009.10.003]

[15] Rezaee M, Assadi Y, Milani Hosseini MR, Aghaee E, Ahmadi F, Berijani S. Determination of organic compounds in water using dispersive liquid-liquid microextraction. Journal of Chromatography A. 2006; 1116(1):1-9. [DOI:10.1016/j.chroma.2006.03.007] [PMID]

[16] Al-Saidi HM, Emara AAA. The recent developments in dispersive liquid-liquid microextraction for preconcentration and determination of inorganic analytes. Journal of Saudi Chemical Society. 2014; 18(6):745-61. [DOI:10.1016/j. jscs.2011.11.005]

[17] Leong MI, Fuh MR, Huang SD. Beyond dispersive liquidliquid microextraction. Journal of Chromatography A. 2014; 1335:2-14. [DOI:10.1016/j.chroma.2014.02.021] [PMID]

[18] Habibi H, Mohammadi A, Kamankesh M. Application and optimization of dispersive liquid-liquid microextraction coupled with high-performance liquid chromatography for sensitive determination of furfural and hydroxymethyl furfural in jarred and canned baby-foods. Nutrition and Food Sciences Research. 2017; 4(1):25-32. [DOI:10.18869/acadpub. nfsr.4.1.25]

[19] Bro R. Multivariate calibration: What is in chemometrics for the analytical chemist? Analytica Chimica Acta. 2003; 500(1-2):185-94. [DOI:10.1016/S0003-2670(03)00681-0]

[20] Singh G, Pai RS. Optimization (central composite design) and validation of HPLC method for investigation of emtricitabine loaded poly (lactic-co-glycolic acid) nanoparticles: In vitro drug release and in vivo pharmacokinetic studies. The Scientific World Journal. 2014; 2014:583090. [DOI:10.1155/2014/583090] [PMID] [PMCID]

[21] Shah VP, Midha KK, Findlay JW, Hill HM, Hulse JD, McGilveray IJ, et al. Bioanalytical method validation-a revisit with a decade of progress. Pharmaceutical Research. 2000; 17(12):1551-7. [DOI:10.1023/A:1007669411738] [PMID]

[22] Santos C, Oppolzer D, Gonçalves A, Barroso M, Gallardo E. Determination of organophosphorous pesticides in blood using microextraction in packed sorbent and gas chromatography-tandem mass spectrometry. Journal of Analytical Toxicology. 2018; 42(5):321-29. [DOI:10.1093/jat/bky004] [PMID]

[23] Soares S, Castro T, Rosado T, Fernández N, Barroso M, Gallardo E. New analytical approach to determine organophosphorus insecticides inblood by dried matrix spots sampling and GC-MS/MS. Analytical and Bioanalytical Chemistry. 2018; 410(30):7955-64. [DOI:10.1007/s00216-018-1417-8] [PMID] 
This Page Intentionally Left Blank 